\title{
Ultrafast Synthesis of Silica-Based Molecular Sieve Membranes in Dielectric Barrier Discharge at Low Temperature and Atmospheric Pressure
}

\author{
Hiroki Nagasawa, ${ }^{\star} \dagger$ Takahiko Kagawa, ${ }^{\ddagger}$ Takuji Noborio, ${ }^{\ddagger}$ Masakoto Kanezashi, ${ }^{\dagger}$ \\ Atsushi Ogata, ${ }^{\prime}$ and Toshinori Tsuru ${ }^{\dagger}$
}

\begin{abstract}
$\dagger$ Chemical Engineering Program, Graduate School of Advanced Science and Engineering, Hiroshima University, 1-4-1 Kagamiyama, Higashi-Hiroshima, Hiroshima 739-8527, Japan

$\ddagger$ Department of Chemical Engineering, Graduate School of Engineering, Hiroshima University, 1-4-1 Kagamiyama, Higashi-Hiroshima, Hiroshima 739-8527, Japan

"Environmental Management Research Institute, National Institute for Advanced Industrial Science and Technology (AIST), 16-1 Onogawa, Tsukuba 305-8569, Japan
\end{abstract}

\section{This PDF file includes:}

S1. Experimental detail

S1.1. Preparation of silica membranes by direct AP-PECVD (Figure S1)

S1.2. Preparation of film samples for FTIR analysis

S1.3. Characterization of AP-PECVD-derived films and membranes

S1.4. Single gas permeation measurements

S2. Supporting Figures and Tables

S2.1. Comparison of membrane synthesis in different PECVD systems (Figure S2)

S2.2. Characterization of direct AP-PECVD membranes (Figures S3 and S4, Tables S1 and S2)

S2.3. Comparison of direct AP-PECVD membranes and other ceramic membranes (Figure S5, Tables S3 and S4)

S3. Theoretical analysis of the gas permeation properties based on the modified gas-translation model (Figures S6 and S7, and Table S5)

S4. Self-limited deposition mechanism (Figures S8-S10) 


\section{S1. Experimental detail}

\section{S1.1. Preparation of silica membranes by direct AP-PECVD}

A porous $\alpha$-alumina tube (outer diameter, $10 \mathrm{~mm}$; inner diameter, $8 \mathrm{~mm}$; length, $30 \mathrm{~mm}$; porosity, 47\%; average pore size, $2 \mu \mathrm{m}$ ) closed at one end, provided by Nikkato Corporation, was used as the membrane substrate. Prior to plasma deposition, a silica-zirconia intermediate layer was formed on the outer surface of the substrate by coating silica-zirconia sol, which was followed by calcination at $550^{\circ} \mathrm{C}$ under an air atmosphere. ${ }^{9}$ This coating procedure was repeated several times to form a defect-free intermediate layer with an average pore size of approximately $1 \mathrm{~nm}$.

AP-PECVD of the silica layer was conducted in a coaxial dielectric barrier discharge reactor driven by AC high-voltage. A schematic of the deposition system is shown in Figure S1. A quartz tube (outer diameter, $14 \mathrm{~mm}$; inner diameter, $12 \mathrm{~mm}$ ) was used as the dielectric barrier, and a copper foil was wrapped around the outside of the quartz tube as the ground electrode. The length of the outer electrode was $50 \mathrm{~mm}$. The $\mathrm{SiO}_{2}-\mathrm{ZrO}_{2}$-coated $\alpha-\mathrm{Al}_{2} \mathrm{O}_{3}$ tubular substrate was placed at the center of the outer electrode. A tungsten rod with a diameter of $2 \mathrm{~mm}$, covered with a glass tube (outer diameter, $3 \mathrm{~mm}$; inner diameter, $2 \mathrm{~mm}$ ), was inserted into the substrate as the high-voltage electrode. The quartz tube, substrate, and inner electrode were arranged in a concentric pattern. Argon gas was employed as the main gas to stabilize the discharge and was fed to the reactor at a fixed flow rate of $500 \mathrm{sccm}$. Hexamethyldisiloxane (HMDSO), as the silicon precursor, was introduced into the feed stream via bubbling of nitrogen as a carrier gas. The flow rate of nitrogen was $1.0 \mathrm{sccm}$, and the bubbling temperature was $0^{\circ} \mathrm{C}$ unless otherwise specified, for which the corresponding vapor pressure of HMDSO was $1.34 \mathrm{kPa}$. Thus, the concentration of HMDSO vapor in the feed stream after mixing with the main gas was $26 \mathrm{ppm}$. The plasma was generated by applying an AC high voltage using an AC highvoltage transformer. (LECIP, M-5). The plug-in power was measured using a digital power meter (Yokogawa, WT310). The applied voltage and input power were $4.5 \mathrm{kV}$ and $3.0 \mathrm{~W}$, respectively. The reactor was externally heated by an electric furnace to control the deposition temperature within the range of 50 to $200^{\circ} \mathrm{C}$. Under plasma operation, the reactor temperature slightly increased; however, the temperature drift was controlled within $\pm 5^{\circ} \mathrm{C}$ of the target temperature. 
(a)

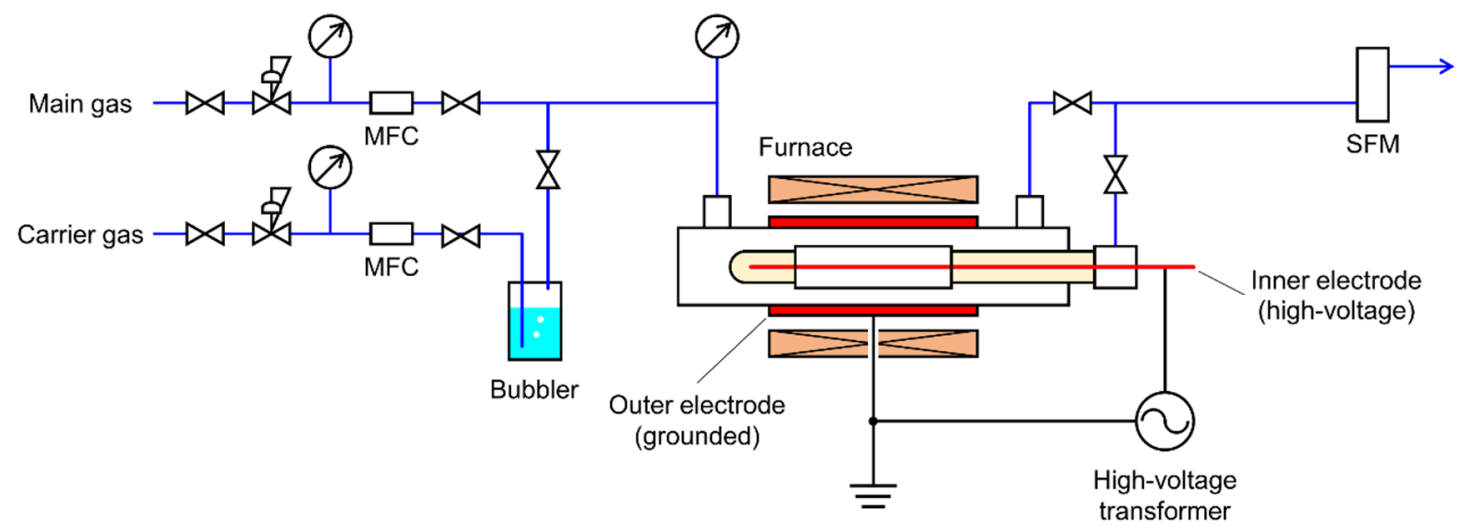

(b)

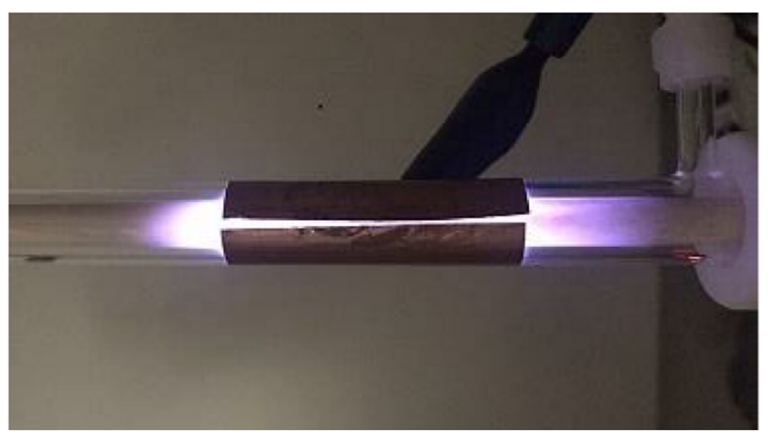

Figure S1. (a) Schematic of the direct AP-PECVD system and (b) digital photo of the deposition reactor during the plasma deposition. 


\section{S1.2. Preparation of film samples for FTIR analysis}

Film samples deposited on an Si wafer were used for the FTIR characterization of the plasmadeposited layer. The film samples were prepared using the same equipment and under the same deposition conditions as that of the membrane synthesis. The $\mathrm{Si}$ wafer was diced into $3 \mathrm{~mm}$ square chips, and subsequently fired in air at $600^{\circ} \mathrm{C}$ to form an oxide layer on the surface. This pretreatment was conducted in order to duplicate the surface characteristics of the porous substrate with an $\mathrm{SiO}_{2}-\mathrm{ZrO}_{2}$ intermediate layer on its outer surface. As the $\mathrm{SiO}_{2}-\mathrm{ZrO}_{2}$ intermediate layer is amorphous and has an oxidized surface, it is reasonable to assume that the deposition process at the surface of the substrate during the membrane synthesis can be reproduced suing the Si wafer after the oxidation treatment. Subsequently, the Si wafer was fixed at the center of the outer surface of the porous substrate that was partially flattened by grinding and was subjected to plasma deposition. The total discharge area at the diameter corresponding to the outer surface of the porous substrate was $15.7 \mathrm{~cm}^{2}$, while that of the $\mathrm{Si}$ wafer was $0.09 \mathrm{~cm}^{2}$, which was small enough to be negligible with respect to the overall discharge behavior. Therefore, the reactive species, including the film-forming intermediate species formed in the gas phase, can be the same as that during the membrane synthesis.

\section{S1.3. Characterization of AP-PECVD-derived films and membranes}

The cross-section of the AP-PECVD-derived membrane was observed by TEM (Hitachi, H-9500) and FE-SEM (Hitachi, S5000). TEM-EDX (JEOL, JEM-ARM200F) was employed to investigate the elemental line scan profile of the membrane. The element depth profile of the membrane was further determined by XPS (Thermo Fisher Scientific, ESCALAB 250Xi, Al-K $\alpha=1486.6 \mathrm{eV}$ ) using $\mathrm{Ar}^{+}$ion sputtering at an etching rate of approximately $3 \mathrm{~nm} \mathrm{~min}^{-1}$. The chemical structure of the films deposited on the Si wafer was analyzed by FTIR (JASCO, FTIR-4100).

\section{S1.4. Single gas permeation measurements}

Single gas permeation was conducted using the same apparatus as that used for the plasma deposition. High-purity gases were fed to the outside of the tubular membrane at $\sim 200 \mathrm{kPa}$, whereas the inside (permeate side) was maintained at atmospheric pressure. The permeation rate was measured using a soap-film flow meter (Horiba, SF-1U). To monitor the development of the permselective layer, the deposition time dependence of the single gas permeances of He (kinetic diameter: $0.26 \mathrm{~nm}$ ), $\mathrm{N}_{2}$ $(0.364 \mathrm{~nm})$, and $\mathrm{SF}_{6}(0.55 \mathrm{~nm})$ were measured between the deposition intervals. The measurement was conducted at the same temperature as the plasma deposition. After confirming that the permeances of $\mathrm{He}, \mathrm{N}_{2}$, and $\mathrm{SF}_{6}$ reached stable values, that is, the permselective layer was fully developed, the single gas permeances of $\mathrm{He}, \mathrm{H}_{2}(0.289 \mathrm{~nm}), \mathrm{CO}_{2}(0.33 \mathrm{~nm}), \mathrm{N}_{2}, \mathrm{CH}_{4}(0.38 \mathrm{~nm})$, and $\mathrm{SF}_{6}$ were measured at temperatures ranging from 50 to $200^{\circ} \mathrm{C}$ to investigate the gas permeation properties through the membranes. 


\section{S2. Supporting Figures and Tables}

\section{S2.1. Comparison of membrane synthesis in different PECVD systems}

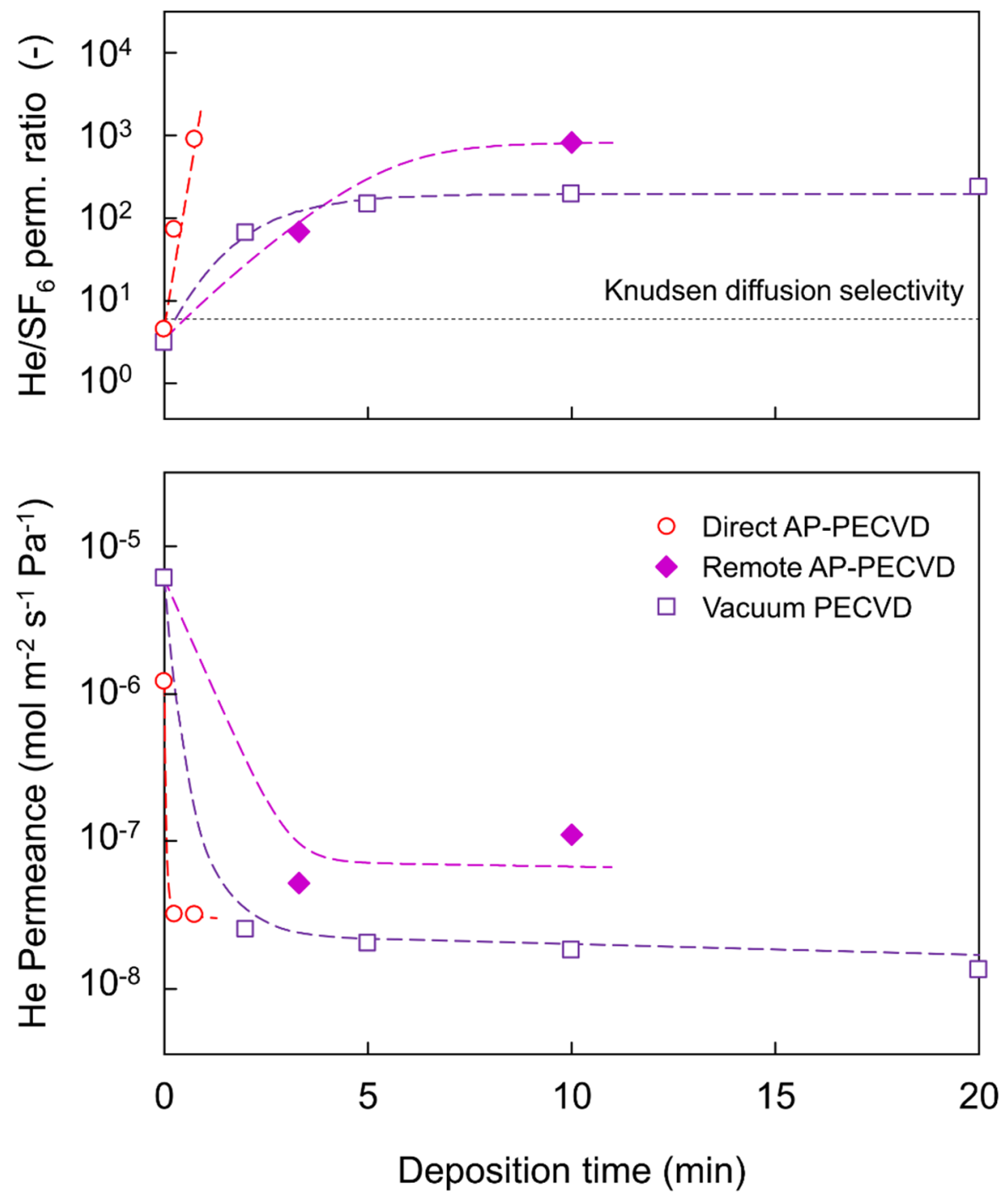

Figure S2. Changes in He permeances and $\mathrm{He}_{\mathrm{S}} / \mathrm{SF}_{6}$ permeance ratios as a function of plasma-deposition time for the HMDSO-derived membranes prepared at room temperature with different PECVD systems: direct AP-PECVD (this work), remote AP-PECVD, ${ }^{7 \mathrm{a}}$ and vacuum PECVD ${ }^{3 \mathrm{c}}$ (open symbols, measured at RT; filled symbols, measured at $50^{\circ} \mathrm{C}$ ). Direct AP-PECVD was performed at an HMDSO concentration of $110 \mathrm{ppm}$. 
S2.2. Characterization of direct AP-PECVD membranes

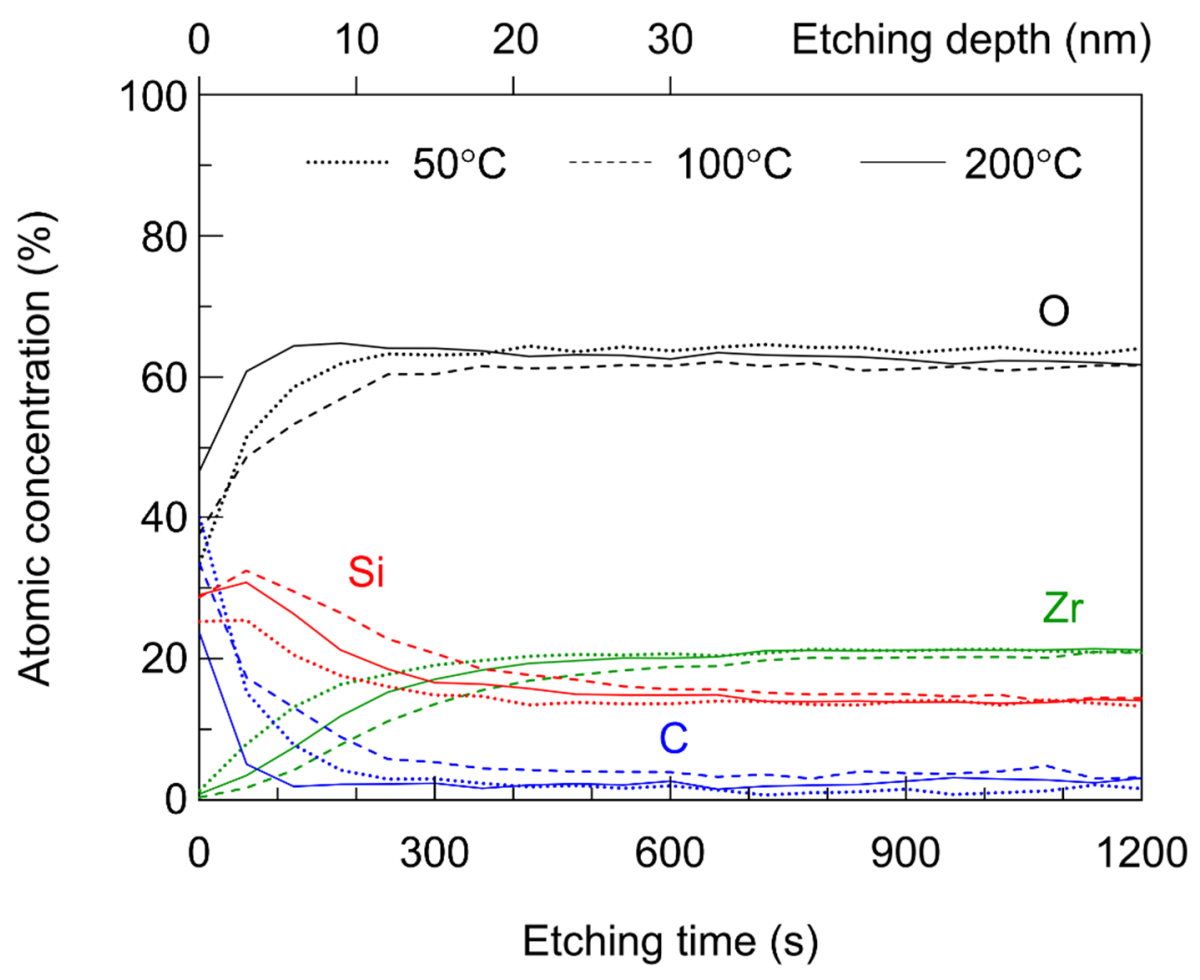

Figure S3. XPS depth profile of the direct AP-PECVD membranes prepared at different deposition temperatures (HMDSO concentration, $26 \mathrm{ppm}$; deposition time, $3 \mathrm{~min}$; etching rate: $3 \mathrm{~nm} \mathrm{~min} \mathrm{~m}^{-1}$ ). 


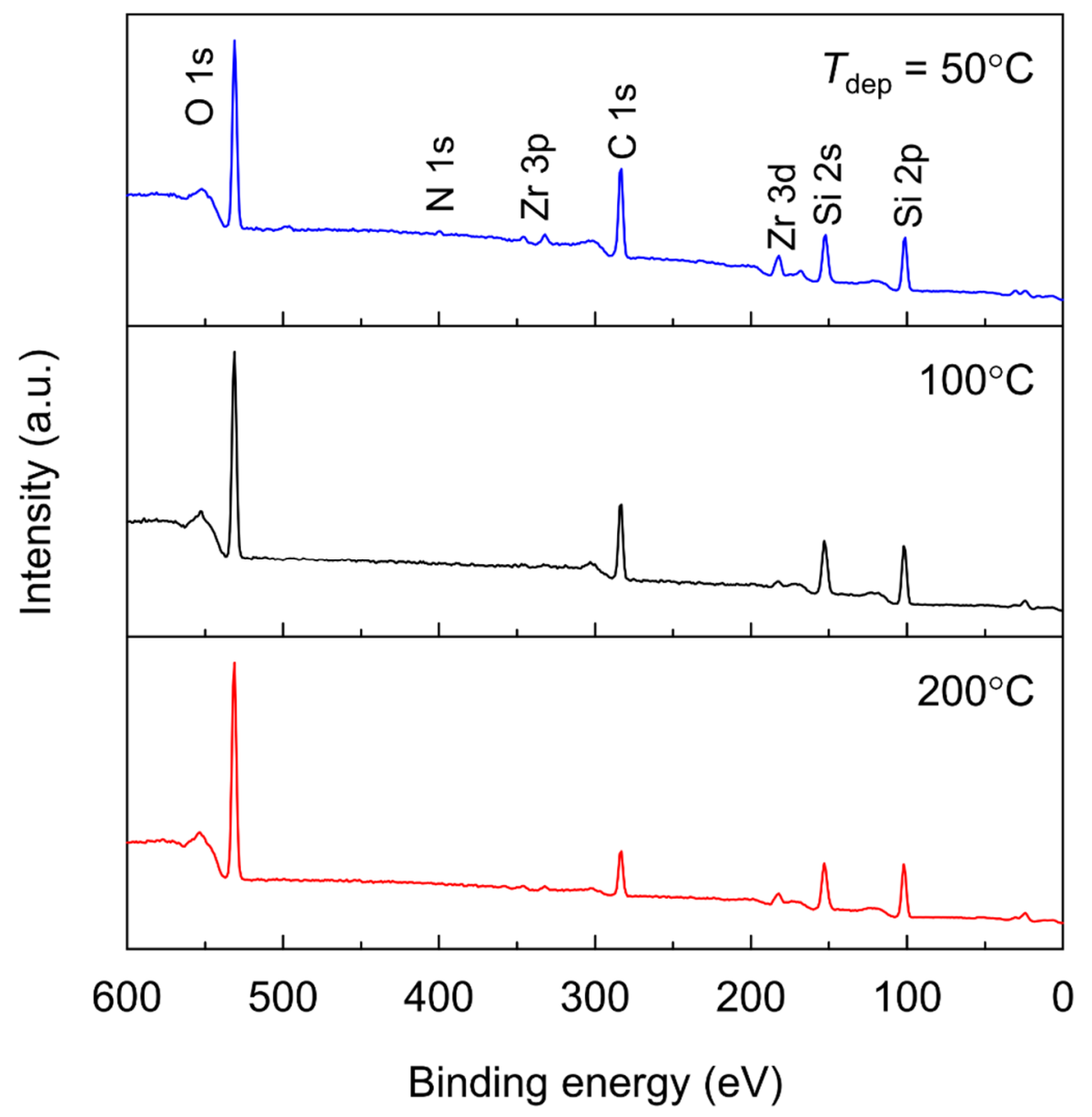

Figure S4. Survey XPS scans of the surface of the direct AP-PECVD membranes prepared at different deposition temperatures (HMDSO concentration, 26 ppm; deposition time, $3 \mathrm{~min}$ ). 
Table S1. Atomic composition of the surface of the direct AP-PECVD membranes prepared at different deposition temperatures (HMDSO concentration, 26 ppm; deposition time, 3 min).

\begin{tabular}{rrrrrrrrrrr}
\hline \multicolumn{1}{l}{$\begin{array}{l}\text { Deposition } \\
\text { temperature }\left({ }^{\circ} \mathrm{C}\right)\end{array}$} & \multicolumn{3}{c}{ Atomic composition (at\%) } & \multicolumn{3}{c}{ Atomic ratio (-) } \\
\hline 50 & & $\mathrm{C}$ & & $\mathrm{O}$ & $\mathrm{N}$ & & $\mathrm{Zr}$ & \multicolumn{2}{c}{$\mathrm{C} / \mathrm{Si}$} & \multicolumn{2}{c}{$\mathrm{O} / \mathrm{Si}$} \\
\hline 100 & 24.9 & 39.6 & 33.2 & 1.0 & 1.3 & 1.59 & 1.33 \\
200 & 28.6 & 33.4 & 37.7 & n.d. & 0.3 & 1.17 & 1.32 \\
HMDSO & 28.9 & 23.6 & 46.7 & n.d. & 0.8 & 0.82 & 1.61 \\
\hline
\end{tabular}

Table S2. XPS deconvolution for Si $2 p$ orbital of the surface of the direct AP-PECVD membranes prepared at different deposition temperatures (HMDSO concentration, 26 ppm; deposition time, $3 \mathrm{~min}$ ).

\begin{tabular}{lrrrr}
\hline $\begin{array}{l}\text { Deposition } \\
\text { temperature }\left({ }^{\circ} \mathrm{C}\right)\end{array}$ & \multicolumn{3}{c}{ Relative peak area (\%) } & \\
$\mathrm{SiO}_{4 / 2}(103.6 \mathrm{eV})$ & $\mathrm{XSiO}_{3 / 2}(102.8 \mathrm{eV})$ & $\mathrm{X}_{2} \mathrm{SiO}_{2 / 2}(101.9 \mathrm{eV})$ \\
\hline 50 & 10.6 & 48.9 & 40.5 \\
& 28.1 & 57.0 & 14.9 \\
& 200 & 34.0 & 54.0 & 12.0 \\
\hline
\end{tabular}




\section{S2.3. Comparison of direct AP-PECVD membranes and other ceramic membranes}

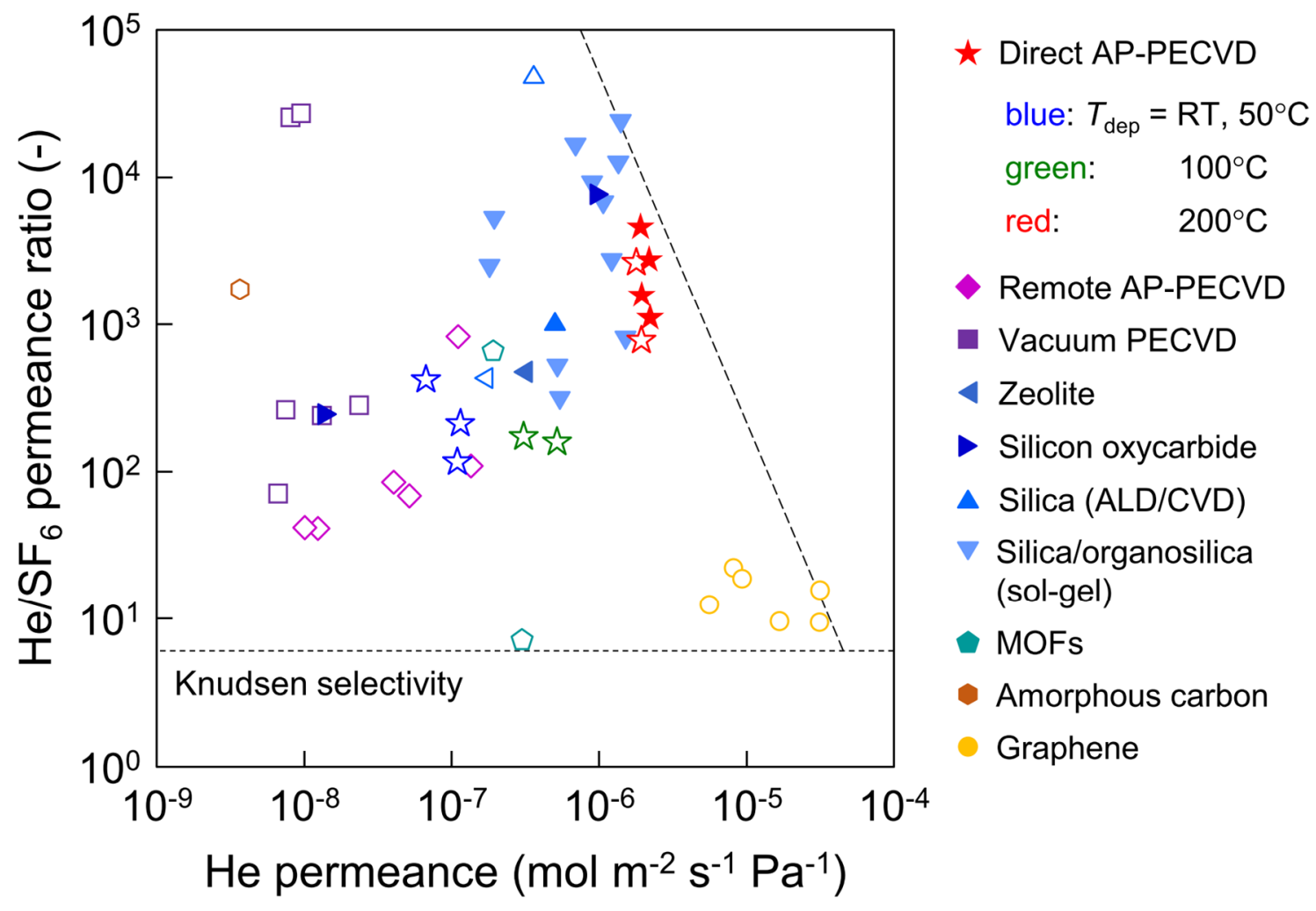

Figure S5. Relationship between the He permeance and $\mathrm{He} / \mathrm{SF}_{6}$ permeance ratio for the direct APPECVD membranes and other representative microporous membranes reported in the literature (open symbols, measured at $\leq 50^{\circ} \mathrm{C}$; filled symbols, measured at $\geq 200^{\circ} \mathrm{C}$ ). Information on the individual data points is presented in Tables S3 and S4. 
Table S3. Gas permeation properties of the direct AP-PECVD membranes presented in Figures 4 and S5.

\begin{tabular}{|c|c|c|c|c|c|c|c|c|c|}
\hline \multicolumn{4}{|c|}{ Deposition conditions } & \multicolumn{6}{|c|}{ Permeation properties } \\
\hline \multirow{2}{*}{$\begin{array}{l}\text { Temperature } \\
\left({ }^{\circ} \mathrm{C}\right)\end{array}$} & \multirow{2}{*}{$\begin{array}{l}\text { Precursor conc. } \\
(\mathrm{ppm})\end{array}$} & \multirow{2}{*}{$\begin{array}{l}\text { Time } \\
\text { (min) }\end{array}$} & & \multirow{2}{*}{$\begin{array}{l}\text { Temperature } \\
\left({ }^{\circ} \mathrm{C}\right)\end{array}$} & \multicolumn{3}{|c|}{ Permeance $\left(\mathrm{mol} \mathrm{m} \mathrm{m}^{-2} \mathrm{~s}^{-1} \mathrm{~Pa}^{-1}\right)$} & \multicolumn{2}{|c|}{ Permeance ratio (-) } \\
\hline & & & & & $\mathrm{He}$ & $\mathrm{H}_{2}$ & $\mathrm{SF}_{6}$ & $\mathrm{He} / \mathrm{SF}_{6}$ & $\mathrm{H}_{2} / \mathrm{SF}_{6}$ \\
\hline RT & 110 & & 0.75 & 50 & 6.70.E-08 & 4.41.E-08 & 1.60.E-10 & 420 & 276 \\
\hline RT & 26 & & 2 & 50 & 1.15.E-07 & 1.05.E-07 & 5.42.E-10 & 212 & 194 \\
\hline 50 & 26 & & 3 & 50 & 1.09.E-07 & 1.24.E-07 & 9.38.E-10 & 116 & 133 \\
\hline 100 & 26 & & 3 & 50 & 3.08.E-07 & 3.28.E-07 & 1.78.E-09 & 173 & 184 \\
\hline 100 & 26 & & 7 & 50 & 5.17.E-07 & 5.45.E-07 & 3.25.E-09 & 159 & 168 \\
\hline 200 & 26 & & 3 & 200 & 2.19.E-06 & 2.76.E-06 & 7.90.E-10 & 2769 & 3500 \\
\hline 200 & 26 & & 5 & 200 & 1.95.E-06 & 2.17.E-06 & 1.23.E-09 & 1590 & 1760 \\
\hline 200 & 26 & & 7 & 50 & 1.93.E-06 & 2.72.E-06 & 2.49.E-09 & 780 & 1100 \\
\hline & & & & 200 & 2.21.E-06 & 2.79.E-06 & 1.99.E-09 & 1100 & 1400 \\
\hline & & & & 200 & 1.91.E-06 & 2.61.E-06 & 4.14.E-10 & 4610 & 6320 \\
\hline
\end{tabular}


Table S4. Gas permeation properties of ceramic membranes reported in the literatures, presented in Figures 4 and S5.

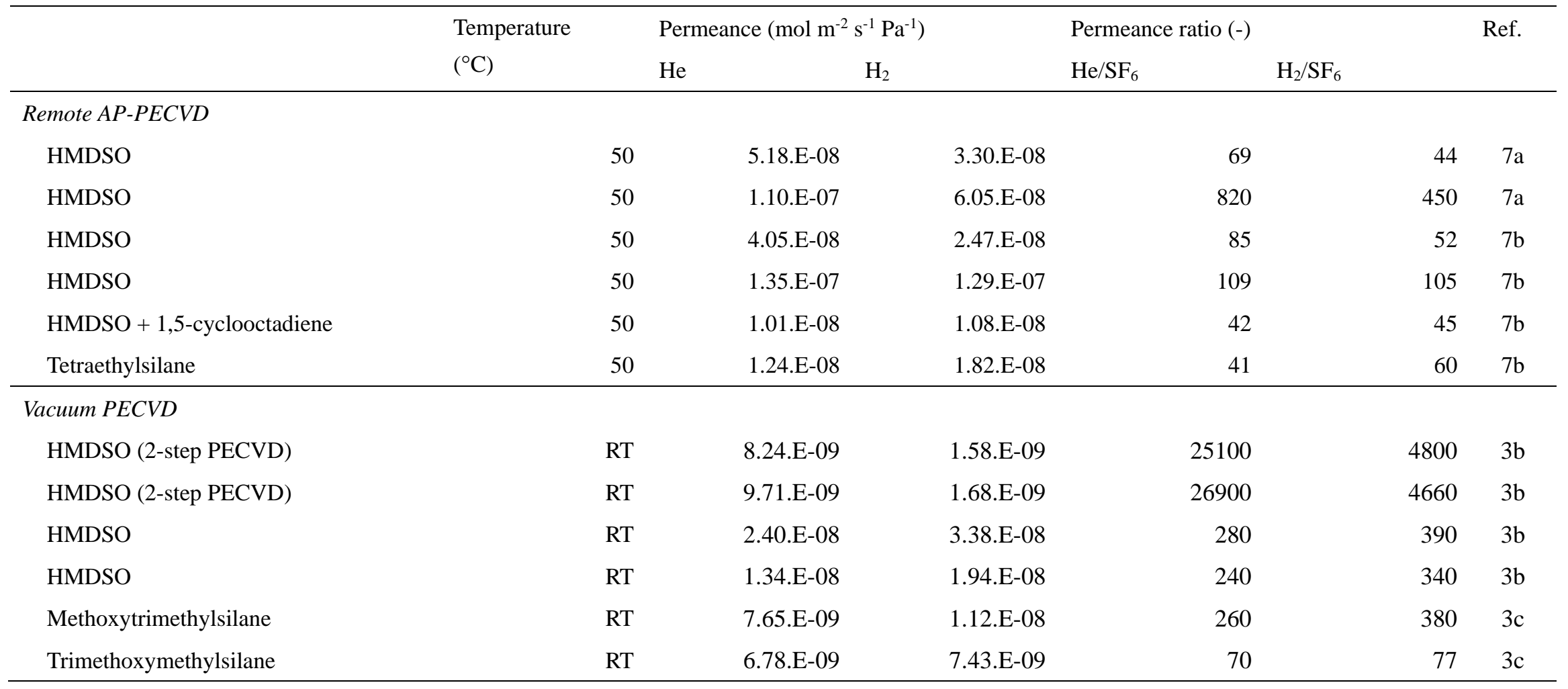


Table S4. (Continued)

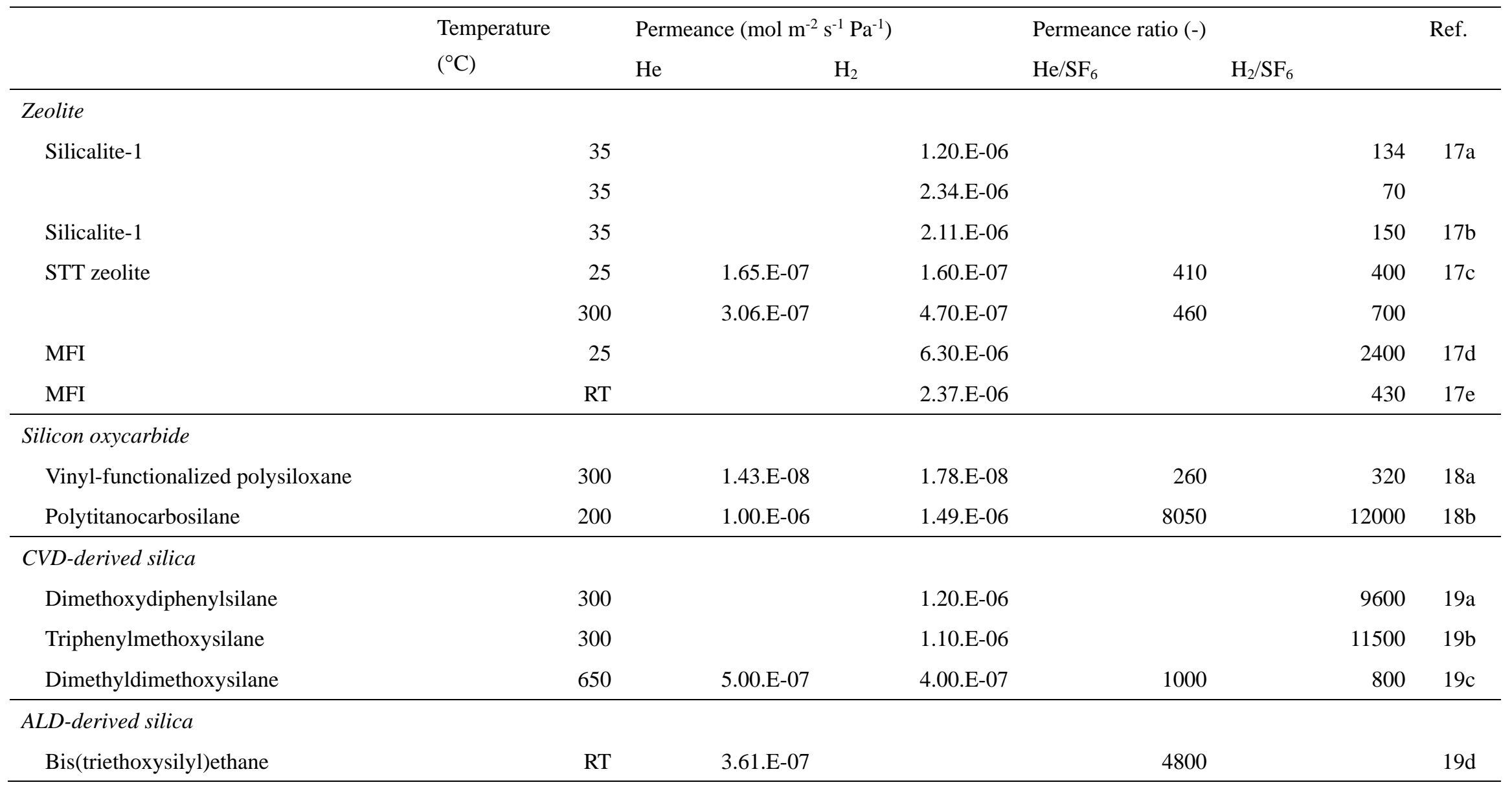


Table S4. (Continued)

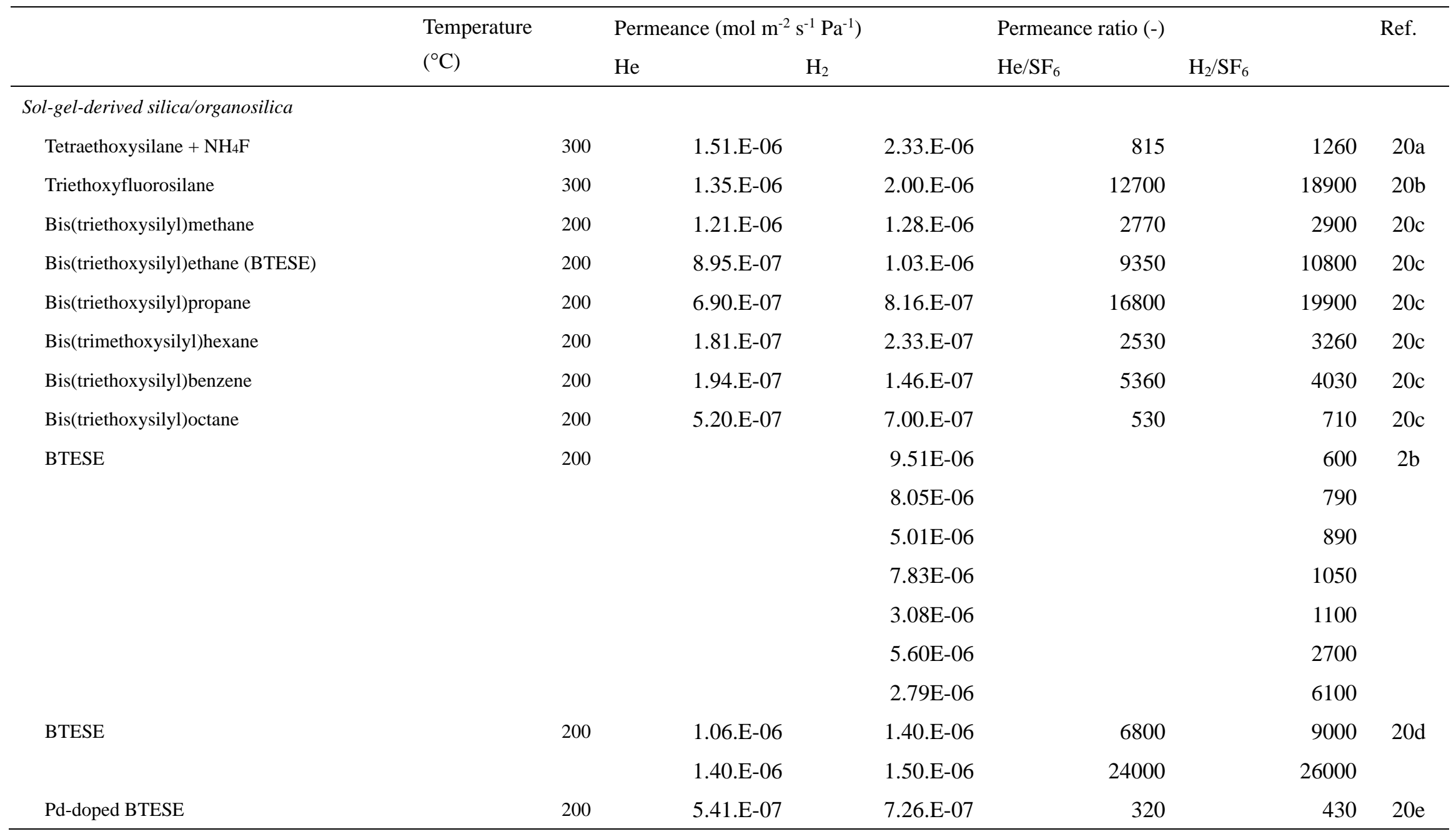


Table S4. (Continued)

\begin{tabular}{|c|c|c|c|c|c|c|c|c|c|c|c|}
\hline & \multirow{2}{*}{$\begin{array}{l}\text { Temperature } \\
\left({ }^{\circ} \mathrm{C}\right)\end{array}$} & & \multicolumn{3}{|c|}{ Permeance $\left(\mathrm{mol} \mathrm{m}^{-2} \mathrm{~s}^{-1} \mathrm{~Pa}^{-1}\right)$} & & \multicolumn{3}{|c|}{ Permeance ratio (-) } & & \multirow[t]{2}{*}{ Ref. } \\
\hline & & & $\mathrm{He}$ & & $\mathrm{H}_{2}$ & & $\mathrm{He} / \mathrm{SF}_{6}$ & & $\mathrm{H}_{2} / \mathrm{SF}_{6}$ & & \\
\hline \multicolumn{12}{|l|}{ Metal organic flameworks } \\
\hline MOF-5 & & 25 & & 3.00.E-07 & & 4.40.E-07 & & 7.1 & & 10.5 & $21 \mathrm{a}$ \\
\hline ZIF-8 & & 35 & & 1.91.E-07 & & 4.72.E-07 & & 660 & & 1620 & $21 b$ \\
\hline ZIF-69 & & 25 & & & & 6.50.E-08 & & & & 13.0 & $21 \mathrm{c}$ \\
\hline \multicolumn{12}{|l|}{ Carbon molecular sieve } \\
\hline PECVD-derived amorphous carbon & & 25 & & 3.70.E-09 & & 4.61.E-09 & & 1750 & & 2200 & 22 \\
\hline \multicolumn{12}{|l|}{ Graphene } \\
\hline \multirow[t]{3}{*}{ Nanoporous single-layer graphene } & & 20 & & 8.3.E-06 & & & & 21.9 & & & $23 a$ \\
\hline & & & & 9.5.E-06 & & & & 18.5 & & & \\
\hline & & & & 3.2.E-05 & & & & 15.4 & & & \\
\hline \multirow[t]{2}{*}{ Nanoporous single-layer graphene } & & 25 & & 1.70.E-05 & & & & 9.4 & & & $23 b$ \\
\hline & & & & 3.18.E-05 & & & & 9.3 & & & \\
\hline
\end{tabular}




\section{S3. Theoretical analysis of the gas permeation properties based on the modified gas- translation model}

For microporous membranes, a theoretical model based on the kinetic theory of gases, referred to as the gas-translation (GT) model, has been developed to describe the gas permeation property through micropores. ${ }^{\mathrm{S} 1}$ This model has been further modified (modified GT model) by considering the sizes of permeating molecules so as to distinguish the geometrical restriction of the movement of permeating molecules of different sizes. ${ }^{10}$ In the modified GT model, the permeance of any gas (component $i$ ) is given as follows:

$$
P_{i}=\frac{1}{3} \frac{\varepsilon}{\tau L}\left(d_{\mathrm{p}}-d_{i}\right) \frac{\left(d_{\mathrm{p}}-d_{i}\right)^{2}}{d_{\mathrm{p}}{ }^{2}} \sqrt{\frac{8}{\pi M_{i} R T}} \exp \left(-\frac{E_{\mathrm{P}, i}}{R T}\right)
$$

where $\varepsilon$ is the porosity, $\tau$ is the tortuosity, $L$ is the membrane thickness, $d_{\mathrm{p}}$ is the mean pore size of the membrane, $d_{i}$ is the kinetic diameter of component $i, M_{i}$ is the molar mass of component $i, E_{\mathrm{P}, i}$ is the activation energy of permeation, $R$ is the gas constant, and $T$ is the absolute temperature. Accordingly, the ideal selectivity for any given gas pair (components $i$ and $j$ ) can be estimated by the ratio of the permeances as follows:

$$
\alpha_{i / j}=\frac{P_{i}}{P_{j}}=\sqrt{\frac{M_{j}}{M_{i}}} \frac{\left(d_{\mathrm{p}}-d_{i}\right)^{3}}{\left(d_{\mathrm{p}}-d_{j}\right)^{3}} \exp \left(-\frac{E_{\mathrm{P}, i}-E_{\mathrm{P}, j}}{R T}\right) \approx \sqrt{\frac{M_{j}}{M_{i}}} \frac{\left(d_{\mathrm{p}}-d_{i}\right)^{3}}{\left(d_{\mathrm{p}}-d_{j}\right)^{3}}
$$

This equation indicates that the ideal selectivity (or permeance ratio) can be approximately expressed as a function of the mean pore diameter. Notably, when the kinetic diameter of component $i$ is smaller than that of component $j\left(d_{i}<d_{j}\right)$, the permeance ratio monotonically decreases with respect to the pore size. By substituting the values of the He/ $\mathrm{N}_{2}$ permeance ratios shown in Figure 2a into Eq. S2, the effective pore size for $\mathrm{He}$ and $\mathrm{N}_{2}$ permeation at $50^{\circ} \mathrm{C}$ can be calculated to be $0.52,0.51$, and $0.86 \mathrm{~nm}$ for the membrane deposited at 50,100 , and $200^{\circ} \mathrm{C}$, respectively. This indicates that the effective pore size for gas permeation was enlarged at higher deposition temperatures.

The porous structure of membranes can be further investigated by extending the analysis based on the modified GT model to the temperature dependence of single gas permeances. The basic equation for the modified GT model in Eq. S1 can be rewritten as follows:

$$
\begin{gathered}
P_{i}=\frac{1}{3} \frac{\varepsilon}{\tau L}\left(d_{\mathrm{p}}-d_{i}\right) \frac{\left(d_{\mathrm{p}}-d_{i}\right)^{2}}{d_{\mathrm{p}}{ }^{2}} \sqrt{\frac{8}{\pi M_{i} R T}} \exp \left(-\frac{E_{\mathrm{P}, i}}{R T}\right) \\
=\frac{k_{0, i}}{\sqrt{M_{i} R T}} \exp \left(-\frac{E_{\mathrm{P}, i}}{R T}\right)
\end{gathered}
$$

where, $k_{0, i}$ is the pre-exponential factor defined as follows: 


$$
k_{0, i}=\frac{\varepsilon}{3 \tau L} \frac{\left(d_{\mathrm{p}}-d_{i}\right)^{3}}{d_{\mathrm{p}}{ }^{2}} \sqrt{\frac{8}{\pi}}
$$

The activation energy of permeation and the pre-exponential factor can be obtained by regression using Eq. S3 with the experimental temperature dependence of the single gas permeance data. According to Eq. S4, the following relationship can be obtained:

$$
k_{0, i}=a\left(d_{\mathrm{p}}-d_{i}\right)^{3}
$$

where $a$ is a constant that depends only on the structure of the membrane pore and is independent of the permeating molecules as follows:

$$
a=\frac{\varepsilon}{3 \tau L d_{\mathrm{p}}^{2}} \sqrt{\frac{8}{\pi}}
$$

Accordingly, the cubic root of Eq. S5 provides the linear relationship between $d_{\mathrm{i}}$ and $k_{0, i}{ }^{1 / 3}$, with a slope of $-a^{1 / 3}$ and an intercept of $a^{1 / 3} d_{\mathrm{P}}$ as follows:

$$
\sqrt[3]{k_{0, i}}=\sqrt[3]{a} d_{\mathrm{p}}-\sqrt[3]{a} d_{i}
$$

Therefore, the effective pore size for gas permeation and the structural parameter can be estimated from the plot of $k_{0, i}{ }^{1 / 3}$ against $d_{i}$.

Here, the analysis based on the modified GT model was applied to the membrane deposited at $200^{\circ} \mathrm{C}$ to investigate the microporous structure of the plasma-deposited layer. The temperature dependence of the single gas permeance for the membrane deposited at $200^{\circ} \mathrm{C}$ is shown in Figure S6, and the estimated values of the activation energy of permeation and the pre-exponential factor are presented in Table S5. As shown in Figure S7, $d_{\mathrm{P}}$ and $a$ for the membrane deposited at $200^{\circ} \mathrm{C}$ are estimated to be $0.567 \mathrm{~nm}$ and $4.41 \times 10^{-4} \mathrm{~nm}^{3}$, respectively. Substituting these values into Eq. S6, together with the thickness of the plasma-deposited layer of $13 \mathrm{~nm}$ determined from the cross-sectional TEM observation (Figure 3a), $\varepsilon / \tau$ is estimated to be $3.46 \times 10^{-3}$. Assuming that the shape of the micropores is cylindrical, where the tortuosity is unity, the porosity is estimated to be $0.35 \%$. It should be noted that the porosity estimated from the modified GT model only reflects the pores that are connected to each other to allow the permeation of gases through the membrane. Moreover, the tortuosity of random network pores is higher than unity and may vary considerably depending on the microstructure of the materials. According to the Monte Carlo simulation of the surface and gas diffusion in a random mesoporous solid conducted by Zalc et al., the geometric tortuosity for the bulk diffusion in the void space showed a large value for the low void fraction (tortuosity of 12.25 at a void fraction of 0.08) as the voids become disconnected. ${ }^{\mathrm{S} 2}$ Therefore, it should be possible to say that the direct AP-PECVD membranes have a porosity of several precent. 


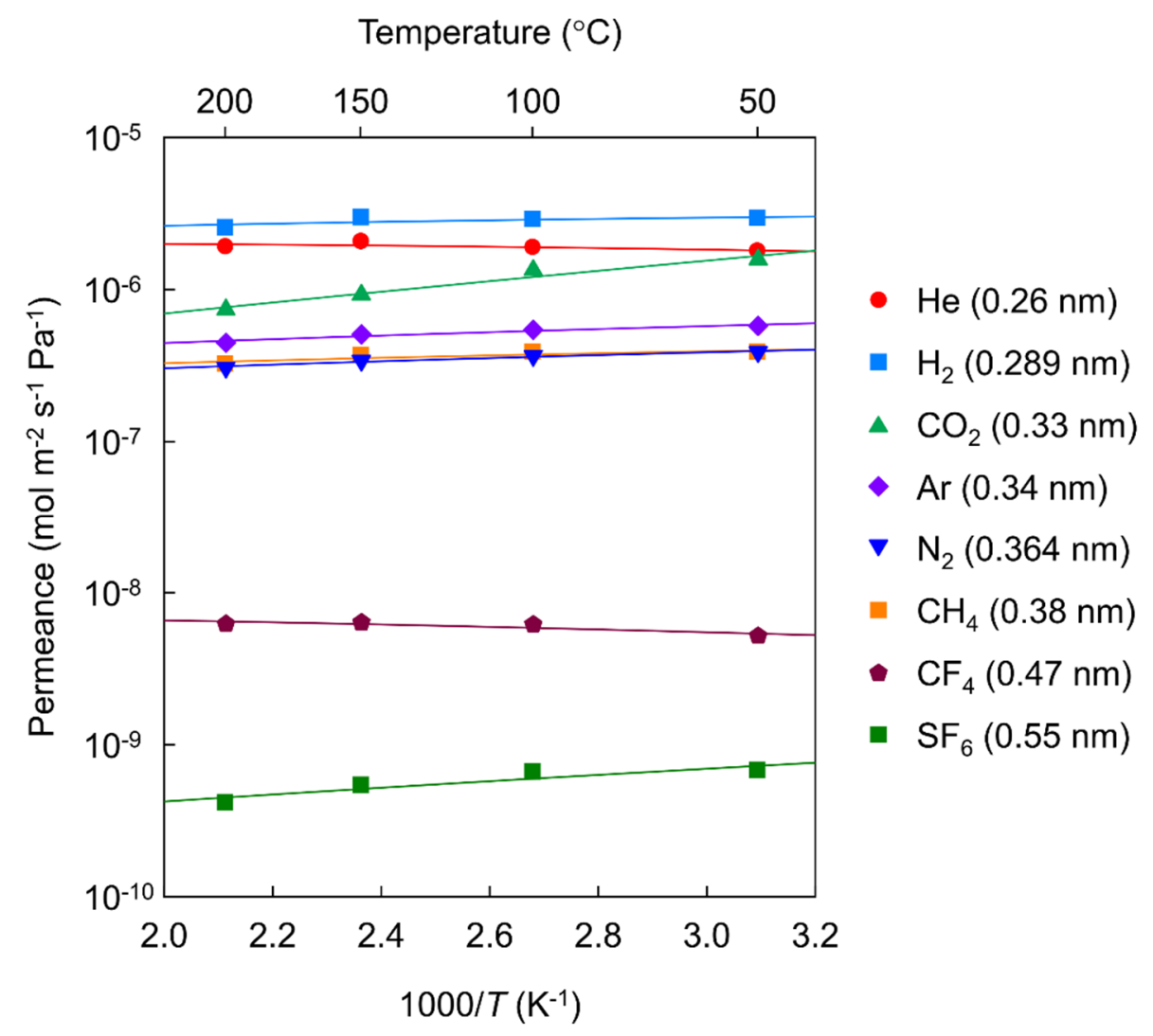

Figure S6. Temperature dependence of single gas permeances for a direct AP-PECVD membrane deposited at $200^{\circ} \mathrm{C}$ with $\mathrm{HMDSO}$ concentration of $26 \mathrm{ppm}$ and deposition time of 7 min (symbols, experimental; solid curve: calculated based on Eq. S3).

Table S5. Estimated values of $k_{0, i}$ and $E_{\mathrm{P}, i}$ for the membrane shown in Figure S6.

\begin{tabular}{lcccccccc}
\hline & $\mathrm{He}$ & $\mathrm{H}_{2}$ & $\mathrm{CO}_{2}$ & $\mathrm{Ar}$ & $\mathrm{N}_{2}$ & $\mathrm{CH}_{4}$ & $\mathrm{CF}_{4}$ & $\mathrm{SF}_{6}$ \\
\hline$k_{0, i}(-)$ & $1.45 \mathrm{E}-05$ & $8.85 \mathrm{E}-06$ & $2.83 \mathrm{E}-06$ & $5.16 \mathrm{E}-06$ & $3.03 \mathrm{E}-06$ & $2.79 \mathrm{E}-06$ & $2.69 \mathrm{E}-07$ & $5.81 \mathrm{E}-09$ \\
$E_{\mathrm{P}, i}\left(\mathrm{~kJ} \mathrm{~mol}^{-1}\right)$ & 2.40 & 0.65 & -4.99 & -0.44 & -0.32 & 0.17 & 3.16 & -2.43 \\
\hline
\end{tabular}




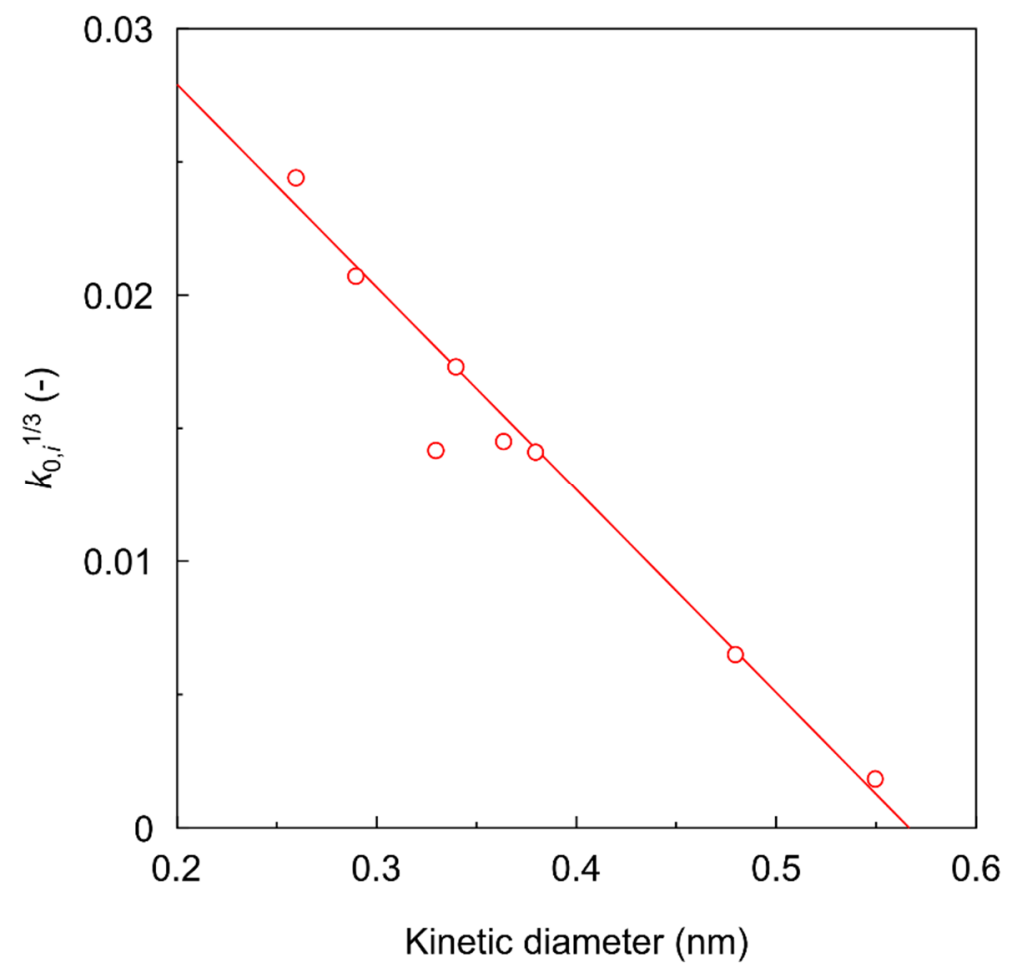

Figure S7. Relationship between the kinetic diameters and $k_{0, i}{ }^{1 / 3}$ for the membrane shown in Figure S6 (symbols, experimental; solid curve: calculated based on Eq. S7). 


\section{S4. Self-limited deposition mechanism}

As shown in Figure 1c, the permeance and permeance ratio of direct AP-PECVD membranes became constant after a certain period of plasma-deposition. A stable and reproducible performance of the resultant membranes, regardless of the plasma-deposition time, is a remarkable characteristic of the proposed direct AP-PECVD approach. In general, the permeance of component $i, P_{i}$, is given by the intrinsic permeability, $\Pi_{i}$, and thickness, $l$, of the separation active layer as follows:

$$
P_{i}=\frac{\Pi_{i}}{l}
$$

Accordingly, the permeance ratio can be expressed as follows:

$$
\frac{P_{i}}{P_{j}}=\frac{\Pi_{i}}{\Pi_{j}}
$$

This equation states that the permeance ratio is independent of the thickness of the separation active layer and can essentially be determined only by the ratio of the intrinsic permeabilities. Therefore, the constant permeance ratio shown in Figure 1c indicates that the intrinsic permeabilities of the separation active layer (the plasma-deposited layer in this case) remained unchanged once the layer was completely formed on the substrate. This implies that a constant permeance could be achieved only if the thickness of the separation active layer remained unchanged even when the plasma deposition was conducted for a longer time. Based on the above discussion, together with the structural characterization of the membranes shown in Figure 3, we hypothesized that the overall growth of the separation active layer is self-limiting, based on the balance of rate processes including diffusion, deposition, and physical etching. Specifically, the growth of the plasma-deposited layer on the substrate is inhibited due to the balance of deposition and physical etching induced by the energetic ion bombardment. Additionally, the penetration of the plasma-deposited layer into the porous substrate is limited due to the balance of deposition and diffusion of the film-forming species inside the substrate pores.

First, we determined the contribution of the physical etching or ion sputtering to the self-limiting deposition based on the experimental approach. In general, during PECVD, ionized species are accelerated across the sheath region, producing an ion flux towards the surface of the substrate. A comprehensive review on the impact of ions on PECVD can be found elsewhere. ${ }^{\mathrm{S} 3}$ For example, Andosca et al. reported that the contribution of ion sputtering increased with increasing ion energy, resulting in a significant decrease in the overall growth rate. ${ }^{\mathrm{S} 4}$ Moreover, the sputtering characteristic strongly depends on the mass of the incident ions; namely, sputtering yields due to ion bombardment increases with increasing mass of the incident ions. ${ }^{\mathrm{S5}}$ For example, the sputtering yields of $\mathrm{He}^{+}$ions are typically more than one order of magnitude lower than those of other noble gases. ${ }^{\mathrm{S}}{ }^{\mathrm{A}} \mathrm{As} \mathrm{Ar}$ was used as

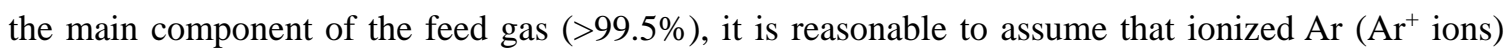
comprises the major species of the ion flux towards the substrate, dominating the sputtering process at the growing surface. Therefore, we attempted to experimentally verify the contribution of ion sputtering to the self-limited deposition mechanism by using different sputtering characteristics of $\mathrm{Ar}^{+}$and $\mathrm{He}^{+}$ 
ions. We conducted direct AP-PECVD of silica membranes at $200^{\circ} \mathrm{C}$ using $\mathrm{He}$ as the main gas instead of Ar without changing the other experimental conditions. As mentioned above, $\mathrm{He}^{+}$ions have a less sputtering ability compared to $\mathrm{Ar}^{+}$ions. Therefore, the membrane prepared using $\mathrm{He}$ as the main gas is expected to have a thicker plasma-deposited layer due to the lower contribution of ion sputtering.

Figure S8 shows the comparison of the deposition time dependence of the He permeance and $\mathrm{He} / \mathrm{SF}_{6}$ permeance ratio for the membranes prepared using $\mathrm{Ar}$ and $\mathrm{He}$ as the main gases. In both cases, the $\mathrm{He} / \mathrm{SF}_{6}$ permeance ratio was over $10^{2}$, resulting in the formation of molecular sieving layers. Nevertheless, unlike the deposition in the Ar-diluted system, the permeance of the membrane prepared using $\mathrm{He}$ as the main gas did not reach a steady value and continued to decrease with increasing deposition time. The He permeance after $30 \mathrm{~min}$ of deposition was $5.3 \times 10^{-7} \mathrm{~mol} \mathrm{~m}^{-2} \mathrm{~s}^{-1} \mathrm{~Pa}^{-1}$, which was one-fourth of that of the membrane prepared using Ar as the main gas. As shown in Figure 9, when these membranes were subjected to cross-sectional SEM observation, an apparent layer (with a thickness of $120 \mathrm{~nm}$ ) due to the plasma deposition was observed only for the membrane prepared using $\mathrm{He}$ as the main gas. This indicates that the growth of the plasma-deposited layer in the Ar-diluted system was considerably inhibited. Notably, the thickness of the plasma-deposited layer formed in the Ar diluted system was only $\sim 13 \mathrm{~nm}$, as confirmed by the TEM observation shown in Figure 3a. Considering the different sputtering characteristics of $\mathrm{Ar}^{+}$and $\mathrm{He}^{+}$ions, it is presumed that the formation of an extremely thin layer can be attributed to the self-limiting deposition owing to the physical etching induced by the bombardment of $\mathrm{Ar}^{+}$ions. 


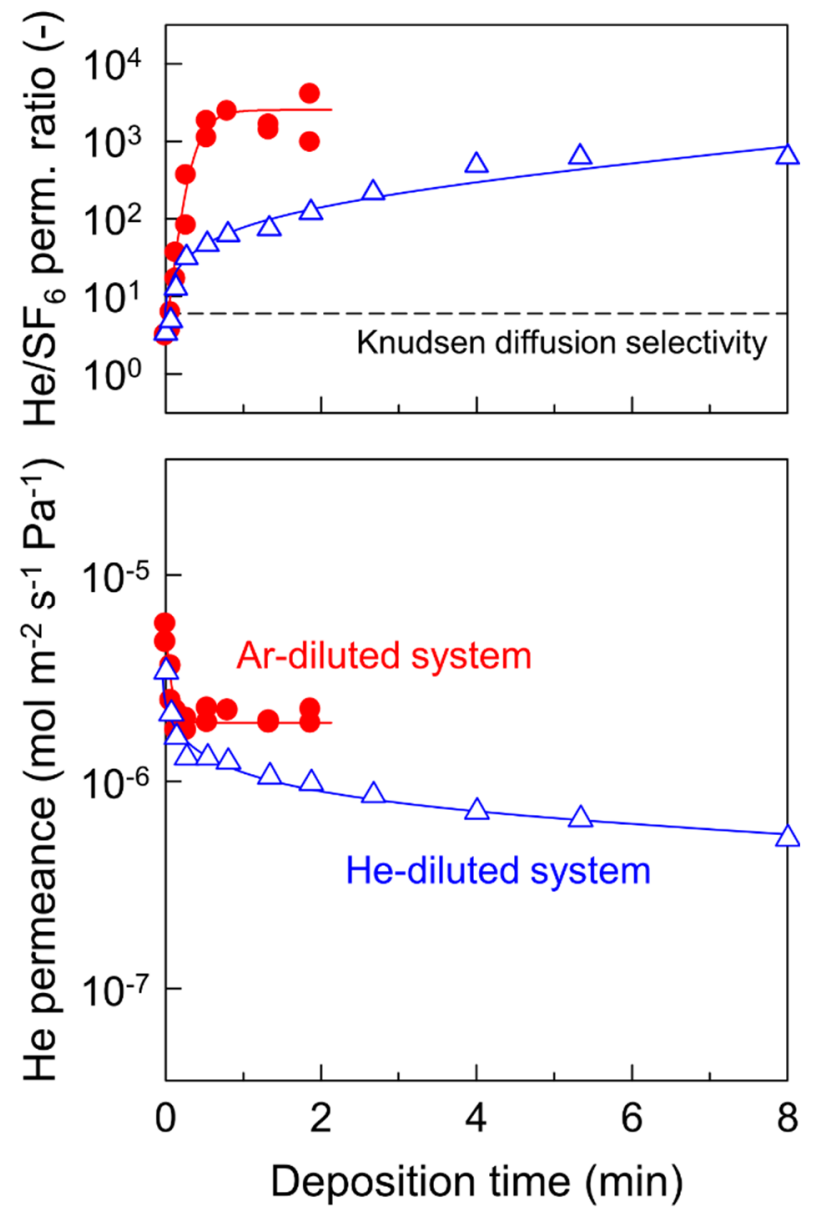

Figure S8. He permeances and $\mathrm{He} / \mathrm{SF}_{6}$ permeance ratios as a function of the plasma-deposition time for the membranes deposited at $200^{\circ} \mathrm{C}$ using $\mathrm{He}$ and $\mathrm{Ar}$ as the main plasma gases.

(a)

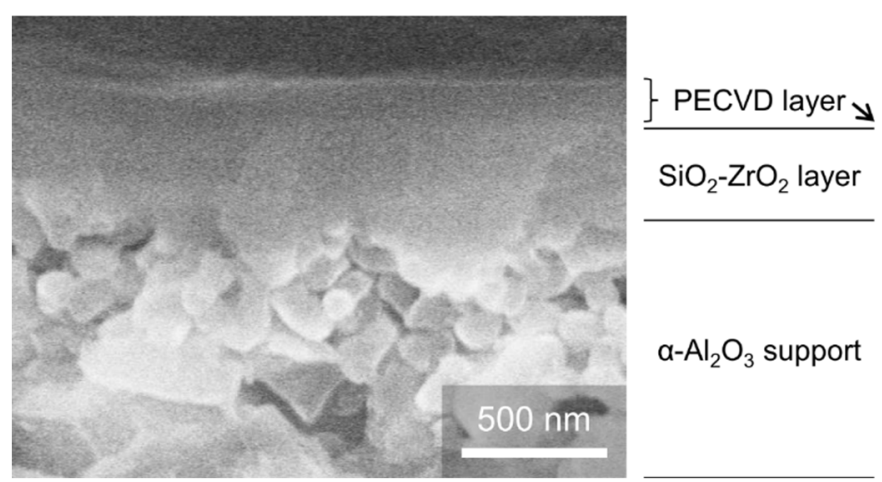

(b)

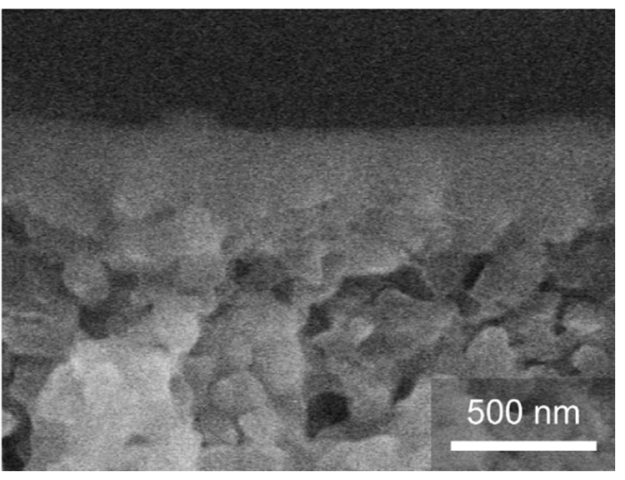

Figure S9. Cross-sectional SEM images of a direct AP-PECVD membrane prepared at $200^{\circ} \mathrm{C}$ using (a) $\mathrm{He}$ and (b) Ar as the main plasma gases. 
We applied a modeling approach to determine the penetration depth, where the film-forming species can diffuse within the pores of the substrate. ${ }^{\mathrm{S} 7}$ We simulated the deposition rate profile along the pore wall by considering a cylindrical pore with a diameter of $d$ as the model system. In PECVD, the reactive species, including the film-forming ones, are generated by the ionization and dissociation of precursors induced by the impact of electrons and ions. As the deposition occurs directly in the discharge region, the film-forming species are generated in the vicinity of the substrate and can readily be transferred to the deposition surface in the proposed AP-PECVD system. Under these conditions, where the film-forming species are sufficiently supplied to the deposition surface, the growth of the plasma-deposited layer in the pores of the substrate is limited by surface reactions. In this case, the mass balance of the film-forming species in the pore can be given as follows, along with the boundary conditions:

$$
\begin{gathered}
D \frac{d^{2} C}{d z^{2}}-\frac{S}{V} k_{s} C=0 \\
C=C_{0} \text { at } z=0 \\
C=0 \text { at } z=\infty
\end{gathered}
$$

where $D$ and $k_{\mathrm{s}}$ are the diffusion coefficient and the surface rection rate of the film-forming species, respectively, and $S / V$ is the surface area to volume ratio of the pore, which is $4 / d$ for a cylindrical pore. $C$ and $C_{0}$ are the concentrations of the film-forming species at depths of $z$ and $z=0$ (at the substrate surface), respectively. As Knudsen diffusion dominates in a nanopore of the substrate, the diffusion coefficient is given by:

$$
D=\frac{1}{3} d \bar{v}
$$

where $\bar{v}$ is the thermal velocity of the film-forming species. The surface reaction rate constant can be expressed by the Hearts-Knudsen equation as:

$$
k_{s}=\frac{1}{4} \bar{v} \eta
$$

where $\eta$ is the sticking probability of the film-forming species. Substituting Eqs. S13 and S14 into Eq. S10 and solving the differential equation, the analytical solution can be obtained as follows:

$$
\frac{C}{C_{0}}=\exp \left(-\frac{\sqrt{3 \eta}}{d} z\right)
$$

This equation indicates that the concentration profile of the film-forming species, which determines the growth rate of the plasma-deposited layer on the pore wall, is only governed by the sticking probability.

Pnetamethyldisiloxane is known to be the dominant film-forming species in PECVD with hexamethyldisiloxane (HMDSO) under non-oxidizing atmospheres such as in an Ar-diluted system, and its sticking probability in the atmospheric pressure dielectric barrier discharge is reported to be near unity. ${ }^{11}$ Substituting the sticking probability of 1 into Eq. S15, the concentration profile of the filmforming species within the substrate pores can be estimated, as shown in Figure S10. Note that a pore 
diameter of $1.0 \mathrm{~nm}$, which is the average pore diameter of the $\mathrm{SiO}_{2}-\mathrm{ZrO}_{2}$ intermediate layer, was employed for the calculation. The concentration of the film-forming species steeply decreased with increasing depth from the surface. The normalized concentration, $C / C_{0}$, decreased to $10^{-2}$ at a depth of $2.0 \mathrm{~nm}$, and $10^{-3}$ at a depth of $4.0 \mathrm{~nm}$. This implies that the growth rate at a depth of a few nanometers beneath the substrate surface is significantly lower than that at the surface. Therefore, the deposition inside the substrate pores was limited to a depth of a few nanometers from the surface. Moreover, the diffusion of the film-forming species into the substrate pores is further limited by the already formed layer, resulting in the self-inhibition of the growth in the pores of the substrate.

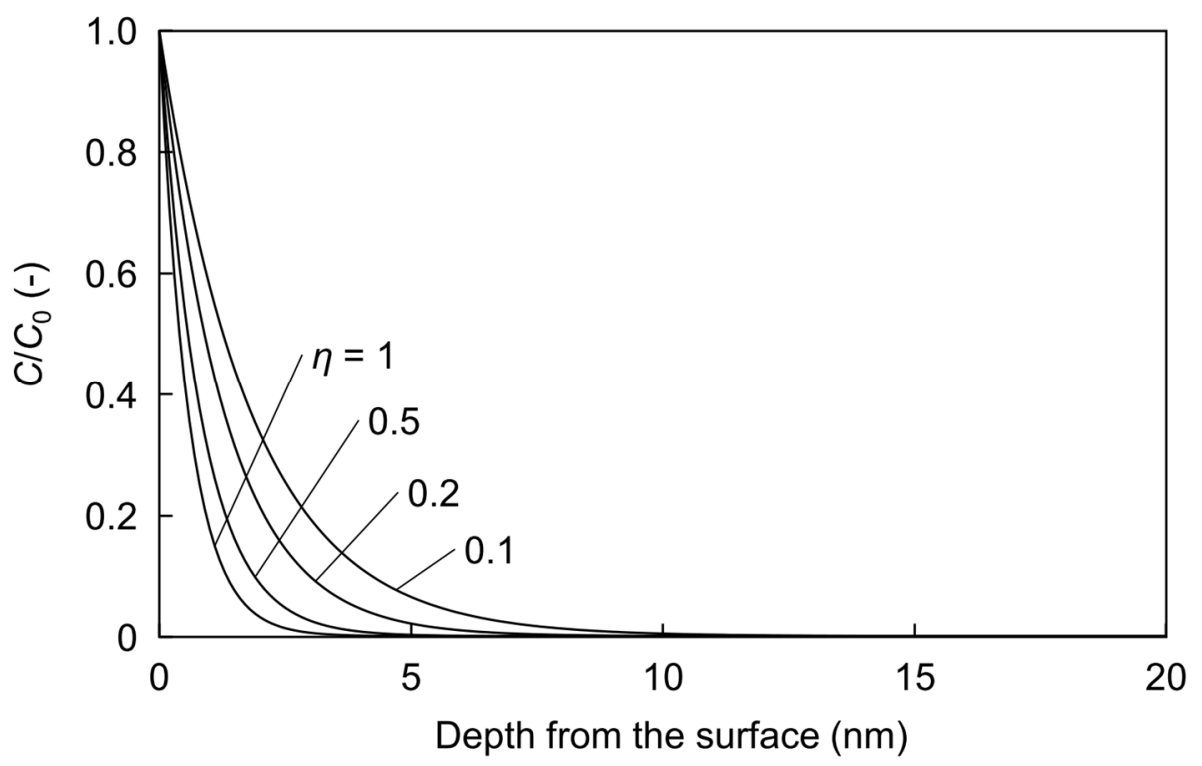

Figure S10. Concentration profile of the film-forming species within the substrate pores as a function of the depth from the surface. 


\section{References}

(S1) (a) Xiao, J.; Wei, J. Diffusion Mechanism of Hydrocarbons in Zeolites - I Chem. Eng. Sci. 1992, 47, 1123-1141. (b) Shelekhin, A. B.; Dixon, A. G.; Ma, Y. H. Theory of Gas Diffusion and Permeation in Inorganic Molecular-Sieve Membranes AIChE J. 1995, 41, 58-67.

(S2) Zalc, J. M.; Reyes, S. C.; Iglesia, E. Monte-Carlo Simulation of Surface and Gas Phase Diffusion in Complex Porous Structures Chem. Eng. Sci. 2003, 58, 4605-4617.

(S3) (a) Martinu, L.; Poitras, D. Plasma Deposition of Optical Films and Coatings: A Review J. Vac. Sci. Technol. A 2002 18, 2619-2645. (b) Vallee, C.; Bonvalot, M.; Belahcen, S.; Yeghoyan, T.; Jaffal, M.; Vallat, R.; Chaker, A.; Lefevre, G.; David, S.; Bsiesy, A.; Posseme, N.; Gassilloud, R.; Granier, A. Plasma Deposition - Impact of Ions in Plasma Enhanced Chemical Vapor Deposition, Plasma Enhanced Atomic Layer Deposition, and Applications to Area Selective Deposition J. Vac. Sci. Technol. A 2020 38, 033007.

(S4) Andosca, R. G.; Varhue, W. J. Adams, E. Silicon Dioxide Films Deposited by Electron Cyclotron Resonance Plasma Enhanced Chemical Vapor Deposition J. Appl. Phys. 1992 72, 1126-1132.

(S5) (a) Sigmund, P. Theory of Sputtering. I. Sputtering Yield of Amorphous and Polycrystalline Targets Phys. Rev. 1969 184, 383-416. (b) Kim, D. H.; Lee, G. H.; Lee, S. Y.; Kim, D. H. Atomic Scale Simulation of Physical Sputtering of Silicon Oxide and Silicon Nitride Thin Films J. Cryst, Growth 2006 286, 71-77.

(S6) (a) Rosenberg, D.; Wehner, G. K. Sputtering Yields for Low Energy $\mathrm{He}^{+}-, \mathrm{Kr}^{+}$, and $\mathrm{Xe}^{+}-\mathrm{Ion}$ Bombardment J. Appl. Phys. 1962 33, 1842-1845. (b) Hine, K.; Yoshimura, S.; Ikuse, K.; Kiuchi, M.; Hashimoto, J.; Terauchi, M.; Nishitani, M.; Hamaguchi, S. Measurement of Magnesium Oxide Sputtering Yields by He and Ar Ions with a Low-Energy Mass-Selected Ion Beams System Jpn. J. Appl. Phys. 2007 46, L113-L1134.

(S7) Komiyama, H.; Shimogaki, Y.; Egashira, Y. Chemical Reaction Engineering in the Design of CVD Reactors Chem. Eng. Sci. 1999, 54, 1941-1957. 